\title{
Transcriptome Profiling of Panc-1 Spheroid Cells with Pancreatic Cancer Stem Cells Properties Cultured by a Novel 3D Semi- Solid System
}

\author{
Zhaocong Yang Yanfeng Zhang Tingting Tang Qinhua Zhu Wanyue Shi \\ Xin Yin Yun Xing Yumeng Shen Yi Pan Liang Jin
}

State Key Laboratory of Natural Medicines, Jiangsu Key Laboratory of Drug Screening, School of life Science and Technology, China Pharmaceutical University, Nanjing, China

\section{Key Words}

Pancreatic cancer stem cells $\cdot 3 \mathrm{D}$ semi-solid culture system • High throughput sequencing • MicroRNAs $\bullet$ Long non-coding RNAs

\begin{abstract}
Background/Aims: Pancreatic cancer remains one of the deadliest human malignancies, the lethality of which may be attributed to the presence of pancreatic cancer stem cells (PCSCs), a small subpopulation of cells existing within pancreatic tumor with high carcinogenesis. Therefore, it is crucial to establish an efficient enrichment and culture system of PCSCs and identify the key genes involved in the regulation of PCSCs. The three-dimensional (3D) liquid suspension mammosphere culture system has been established for enrichment and culture of PCSCs in vitro as the cell spheres are likely to originate from individual cell clone, but it has been challenged because the cell spheroids could be a result of cell aggregation. Methods: We optimized the existing culture system by adding methylcellulose to create a 3D semi-solid system which prevented the non-specific aggregation. Then we identified the CSC properties of Panc-1 spheroid cells cultured by this system by detecting the genes associated with stemness and by evaluation of the tumorigenicity in vitro and in vivo through invasion, migration and xenograft experiments methods. Subsequently, we performed highthroughput sequencing (HTS) of the Panc-1 spheroid cells. Results: We confirmed the PCSCs properties and high malignancy of the Panc- 1 spheroid cells enriched by our novel 3D semisolid system both in vitro and in vivo. Hundreds of mRNA, microRNA (miRNA) and dozens of long non-coding RNA (LnCRNA) were identified to be differentially regulated in PCSCs-like Panc-1 spheroid cells compared with their parental cells by HTS. Conclusions: Our results demonstrate an efficient enrichment and culture system for Panc-1 spheroid cells with the PCSCs properties. The differentially expressed genes and their targets identified by the HTS of the Panc-1 spheroid cells can serve as new potential biomarkers for pancreatic cancer diagnosis and targeted therapy.

Zhaocong Yang and Yanfeng Zhang contributed equally to this work.

Yi Pan

and Liang Jin

State Key Lab. of Natural Medicines, Jiangsu Key Lab. of Drug Screening, School of life Science and Technology, China Pharmaceutical University. 24 Tongjiaxiang, Nanjing, Jiangsu province, (PR China); E-Mail ljstemcell@cpu.edu.cn /1020162543@cpu.edu.cn
\end{abstract}




\section{Cellular Physiology Cell Physiol Biochem 2018;47:2109-2125 \\ and Biochemistry Published online: July 04, $2018 \quad \begin{aligned} & \text { DOI: 10.1159/000491479 } 2018 \text { The Author(s). Published by S. Karger AG, Basel } \\ & \text { www.karger.com/cpb }\end{aligned}$}

Yang et al.: Transcriptome Profiling of Pancreatic Cancer Stem Cells

\section{Introduction}

Pancreatic cancer is a highly lethal disease with a 5-year survival rate from less than $6 \%$. The prognosis of pancreatic cancer patients remains poor due to its late diagnosis, silent nature, low surgical resectability rates, and resistance to standard chemotherapy and radiation [1]. Currently, there are very limited treatment options for pancreatic cancer, and the causes of poor survival of pancreatic cancer patients are still unclear. Emerging evidences suggest that a small number of cells known as cancer stem cells (CSCs) are present in tumor tissues, which may contribute to tumor development, progression, and recurrence. CSCs are those multipotent cells exhibiting self-renewal capacity, multilineage differentiation ability and high carcinogenesis, and have been identified in several types of human cancers including pancreatic cancer [2, 3]. CSCs are not only considered as tumor-initiating cells but also as cells that promote tumor development and therapy resistance.

Pancreatic Cancer Stem Cells (PCSCs) were first identified by Simeone et al. in 2007. This small subset of cells with the CD44+CD24+ESA+ phenotype make up only $0.2 \%-0.8 \%$ of total pancreatic cancer cells. They obtain the stem cell properties of self-renewal, the ability to produce differentiated progeny. They also display a 100 -fold enhanced tumorigenic potential compared with none triple positive cells in vivo [2]. A subpopulation of CD133+ pancreatic cancer cells were also reported to have CSCs properties and highly resistance to standard chemotherapy [3]. Growing researches indicate PCSCs play an important role in the occurrence and development of pancreatic cancer, and are the underlying cause of chemotherapy resistance and metastasis of pancreatic cancer. So PCSCs emerge as an excellent target for developing effective novel therapeutic approaches of pancreatic cancer.

The three-dimensional (3D) spatial conformation for spheroid culture is a common way to culture CSCs in vitro, because the expansion of CSCs is through the way of clonal expansion in vitro and the cell spheres are more likely to originate from individual cell clones [4]. The resulting CSCs were not only spherical in shape, but also possessed many features like that in solid tumors such as higher cell proliferation, migration and chemoresistance ability, which were not observed in normal monolayer cultures [5]. However, the common liquid suspension mammosphere culture system has been challenged because free movement of single cell can lead to non-specific cell aggregation and generate the cell spheroids [6]. Therefore, some teams tried to establish the semi-solid culture system to culture CSCs in vitro by adding collagen and so on to limit cell mobility and aggregation [7], yet still some limitations. To better study PCSCs, it is strongly needed to establish an optimized system for PCSCs culture and enrichment.

High-throughput sequencing (HTS) has made it possible to detect the genetic variants throughout the human genome and has made a revolution in cancer research. HTS is extensively used to profile RNA transcriptome in cancer cells including CSCs [8], which can help accurately and efficiently quantify the aberrantly expressed coding mRNAs and non-coding RNAs (miRNAs and LncRNAs). So this technology has potential for discovering novel mRNAs, miRNAs or LncRNAs and may subsequently lead to the discovery of novel cancer biomarkers and therapeutic targets. So far, there are already some miRNAs and LncRNAs that have been reported to be differentially expressed in pancreatic cancer, which contribute to the proliferation, invasion and stem cell-like phenotype of pancreatic cancer [9]. Nevertheless, key genes and specific non-coding RNAs involved in biological properties of PCSCs have yet to be fully identified.

In this study, we improved the 3D culture system of Panc-1 pancreatic cancer cell line by adding methylcellulose to create a 3D semi-solid system which prevent the non-specific aggregation. To investigate the CSCs properties of the Panc-1 spheroid cells enriched by this novel system, we examined the expression of CSCs markers and the ability of the spheroid formation, self-renewal, proliferation, metastasis, drug resistance in vitro, and the tumorigenicity in mice. We also applied HTS to generate and compare the sequencing results between PCSCs-like Panc-1 spheroid cells and their parental cells, in which we found some differentially expressed mRNAs, miRNAs and LncRNAs. Due to the limited knowledge of the 
roles of RNAs in the regulation of PCSCs, our finding, with the help of Gene Oncology (GO) and Kyoto Encyclopedia of Genes and Genomes (KEGG) analysis and co-expression analysis of differentially expressed RNAs, will provide a list of new potential biomarkers for pancreatic cancer diagnosis and targeted therapy.

\section{Materials and Methods}

Ethics approval and consent to participate

Male BALB/c nude mice (4-weeks-old) were purchased from Vital River Laboratory Animal Technology Company (Beijing, China). All care and handling of animals were carried out according to the international laws and policies (EEC Council Directive 86/609, 1987) and approved by the animal ethics committee of China Pharmaceutical University (Nanjing, China). Reference Number: 2162326.

\section{Availability of data and materials}

All data generated or analyzed during this study have been included in this published article (for all online suppl. material, see www.karger.com/doi/10.1159/000491479) and its supplementary information files.

\section{Cell line and monolayer culture}

Pancreatic cancer cell line Panc-1 was obtained from the American Type Culture Collection (Catalog number: CRL-1469 ${ }^{\mathrm{TM}}$ ) and cultured in DMEM (Gibco) supplemented with $10 \%$ foetal bovine serum (FBS) (Gibco), $100 \mathrm{U} / \mathrm{ml}$ penicillin and $100 \mu \mathrm{g} / \mathrm{ml}$ streptomycin (Gibco) at $37^{\circ} \mathrm{C}$ under a $5 \%$ humidified $\mathrm{CO2}$ atmosphere. All experiments were performed with cell cultures that were $70 \%$ confluent.

Scanning electron microscope imaging of spheroids and monolayer

For the analysis of the ultrastructure of the Panc-1 spheroid cells and monolayer parental cells, scanning electron microscope (SEM) was performed as described elsewhere [8]. The samples were examined under SEM (JSM-6400).

\section{Sphere formation assay}

The Panc- 1 cells were plated in 24-well ultralow attachment plates (Corning at a density of 2300 cells/ $\mathrm{ml}$ in DMEM:F12 (Gibco) supplemented with 1\% methylcellulose (1500cP, Sigma), 1\% FBS, $20 \mathrm{ng} / \mathrm{ml}$ EGF (PeproTech), 100 ng/ml bFGF (PeproTech), 2\% B27 supplement (Gibco), 1\% ITS (5 mg/L insulin, 5 mg/L transferrin. $5 \mu \mathrm{g} / \mathrm{L}$ sodium selenite; Gibco), $100 \mathrm{U} / \mathrm{ml}$ penicillin and $100 \mu \mathrm{g} / \mathrm{ml}$ streptomycin (Gibco) at $37^{\circ} \mathrm{C}$ under a $5 \%$ humidified $\mathrm{CO}_{2}$ atmosphere. The 11-day-old spheres were harvested using $40 \mathrm{~mm}$ cell strainers, dissociated to single cell with Accutase Solution (Sigma) for the following self-renewal assay. The differentiation of tumorsphere-derived cells was induced by being cultured in DMEM supplemented with $10 \%$ FBS.

\section{Self-renewal capability assay}

For 3D culture, after being cultured for 11 days, the colonies were counted and harvested. After dissolved in Accutase Solution, cells were counted and re-plated in the same condition. This process was repeated for 4 times and the sphere formation rate was counted.

\section{Flow cytometry}

To detect the PCSCs subpopulations, the following antibodies against the surface markers were used: anti-CD44-APC, anti-CD24-PE, IgG1-PE, IgG1-APC, anti-CD133 (BD), anti-ESA-PE-Cyanine7, IgG1-PECyanine7 (eBioscience). The cells were stained with the antibodies for $10 \mathrm{~min}$ in the dark at $4^{\circ} \mathrm{C}$ according to the manufacturer's protocol and analyzed with a FACS Calibur Flow Cytometer (BD). Data were analyzed with BD FACS Diva software.

RNA isolation and quantitative RT-PCR

Total RNAs were extracted using TRIZOL Reagent (Invitrogen). cDNA was synthesized using either All-In-One RT MasterMix (ABM) according to the manufacturer's protocol. Quantitative RT-PCR (qRT-PCR) 


\section{Cellular Physiology Cell Physiol Biochem 2018;47:2109-2125 \\ \begin{tabular}{l|l} 
and Biochemistry POI: 10.1159/000491479 & $\begin{array}{l}\text { () 2018 The Author(s). Published by S. Karger AG, Basel } \\
\text { www.karger.com/cpb }\end{array}$ \\
\hline
\end{tabular} \\ Yang et al.: Transcriptome Profiling of Pancreatic Cancer Stem Cells}

was performed using EvaGreen $2 \times$ qPCR MasterMix (ABM) on Light Cycler 480 II (Roche, Switzerland) in triplicate samples. The RT-PCR results were normalized to the threshold cycle (Ct) of GAPDH or U6, referred to as $\Delta \mathrm{Ct}$. The fold change was expressed as $2^{-\Delta \Delta \mathrm{Ct}}$.

Immunofluorescence assay

Immunofluorescence assay for CSCs markers were performed as described elsewhere [8].The monoclonal antibodies, including anti-Sox-2, anti-Oct-4, anti-Nanog antibodies were used.

Cell proliferation assay

To analyze the ability of cell proliferation, MTT assay and plate colony assay were performed as described elsewhere [10].

Wound healing assay

To analyze the ability of cell motility, wound healing assay was performed based on published method [11].

Transwell invasion and transmembrane migration assay

Cell invasion assay were performed as described elsewhere [8]. For the cell transmembrane migration assay, all the steps were carried out similarly to those in the invasion assay except for the Matrigel coating.

Drug sensitivity assays

The cells were seeded in 96-well microplates at the density of $1 \times 10^{4}$ cells/well on the same growth medium based on published method [12]. Different concentrations of Doxorubicin, Gemcitabine and Oxaliplatin $(0 \mu \mathrm{M}$ to $160 \mu \mathrm{M})$ were added $200 \mu \mathrm{L} /$ well. After incubating for $48 \mathrm{~h}$, the MTT assay was performed.

\section{In vivo xenograft experiments}

Male BALB/c nude mice (4-weeks-old) were purchased from Vital River Laboratory Animal Technology Company (Beijing) and maintained in SPF level animal room. All the animal experiments were approved by the Ethics Committee of China Pharmaceutical University, Nanjing, China. Panc-1 parental and spheroid single cell suspensions $\left(2 \times 10^{6}\right.$ cells in a total volume of $200 \mu \mathrm{L}$ PBS medium with $50 \%$ Matrigel $)$ were injected into the right axilla of mice, respectively. The tumor was measured every 4 days and its volume was calculated according to the formula. Four weeks later, all mice were sacrificed and the tumors were stripped. The tumor tissue was embedded in paraffin for hematoxylin and eosin (H\&E) staining and immunohistochemical staining.

High throughput sequencing

Three batches of Panc-1 parental and spheroid samples were collected in parallel. Before the highthroughput sequencing, the three batches of each kind of sample were pooled together and mixed, then the total RNA was extracted. All sequencing and data analysis were conducted by Genergy Inc (Shanghai, China).

\section{Statistical analysis}

These above experiments were performed in triplicate, and each was repeated several times. The results are presented as the means \pm SEM of at least three independent experiments. Statistical analysis was performed using student independent $t$-test via GraphPad Prism 5 software between experimental groups. The level of significance was set at $P<0.05\left(^{* *}\right)$.

\section{Results}

Formation of homogeneous PCSCs-like Panc-1 spheroid cells with self-renewing capability in the modified 3D semi-solid system

To avoid the problems existing in 3D liquid system, such as non-specific cell aggregation caused by free movement of single cell and difficulty to form optimal size 
without extracellular matrix to support spheroids growth. We optimized the medium by adding methylcellulose referring to the system established by our laboratory used to culture pancreatic progenitor cell [13]. Methylcellulose is a kind of long-chain polysaccharides which can form compact grid in the liquid suspension medium while restrict the movement of single cells, yet soft enough to allow colony formation. By optimizing the cell concentration, we can ensure that there is no more than one cell in a grid, thus to prevent non-specific cell aggregation. We used this 3D semi-solid culture system to culture and enrich Panc-1 tumor spheroids from human pancreatic cancer cell line Panc-1 (Fig. 1A).

When observed under bright field and SEM, the parental Panc-1 cells grew as adherent epithelial-like monolayer cells of polygonal shape with clear and sharp boundaries in between and were connected to each other through cell-cell junction (Fig. 1B). Under 3D semi-solid culture condition, the Panc-1 cells grew into 3D non-adherent spheroids within 11 days. The spheroids were mostly homogeneous in size and reached 100 to $200 \mu \mathrm{m}$ in diameter on day 11. SEM images at $1000 \times$ magnification revealed aggregation of hundreds of cells originated from the same individual cell which constitutes the spheroidal structure. Higher magnification at $4000 \times$ further revealed that the cells in the spheroid were held together by cell-cell junctions throughout the whole structure. Presence of the micropores (arrowheads) on the interior of the spheroid might allow the diffusion of nutrients and oxygen to the inner cells. To assess its self-renewal capacity, the initially formed spheroids were harvested and dissociated into single cells and were grown in 3D semi-solid medium at a lower density of 2000 cells/well as described in the methods. In this condition, cells were grown as nonadherent 3D clusters with increasing size from day 1 to day 11 (Fig. 1D). The secondary spheroids were subsequently cultured up to four passages and the spheroid-forming efficiency remained relatively constant from the beginning through the end (Fig. 1C). The capacity to form spheroids at constant efficiency through generations provided an evidence that the cells have acquired extended self-renewal ability.

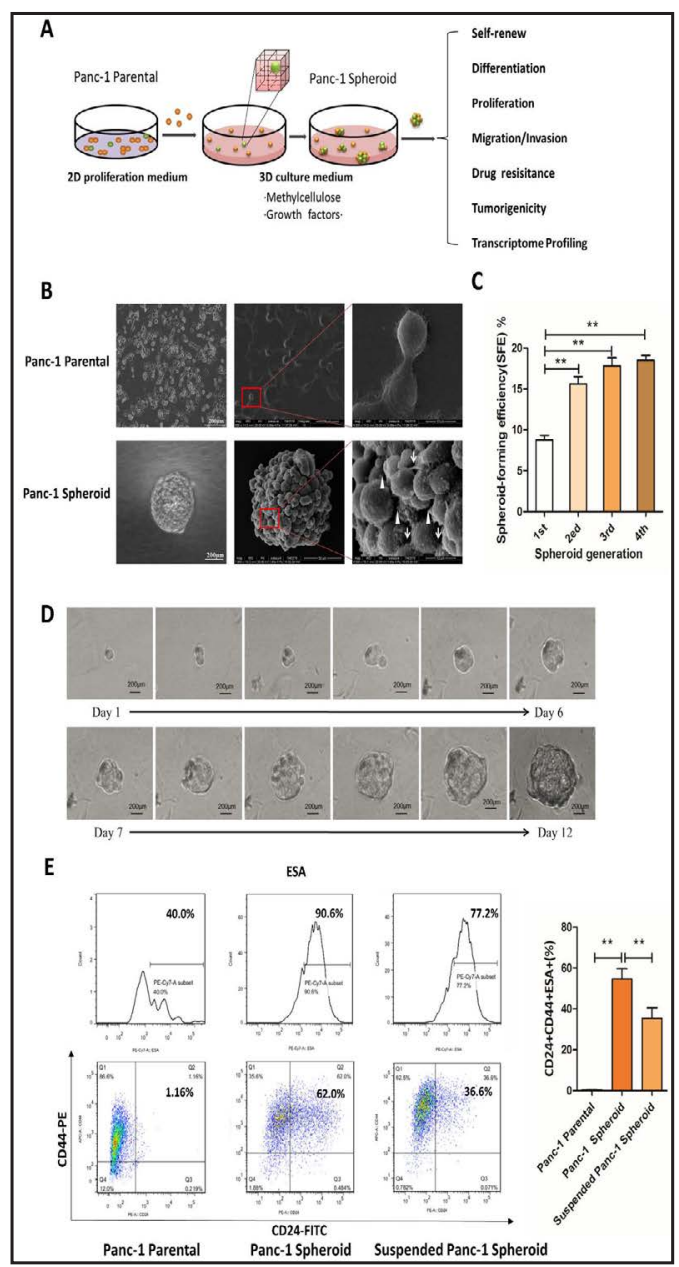

Fig. 1.Establishment of a novel CSC-like Panc-1 enrichment and culture system.(A) Schematic of CSCs-like Panc-1 culturing system. (B) Formation of Panc-1 monolayer under 2D and spheroid cells under 3D conditions in culture flash under bright field (Magnification: 100×, scale bar: $200 \mu \mathrm{m}$ ) and SEM (Magnification: $600 \times$, scale bar: $50 \mu \mathrm{m}$ and Magnification: $4000 \times$, scale bar: $10 \mu \mathrm{m}$ ) respectively. (C) Spheroid-forming efficiency of spheroids from the first to the fourth generation. The number of spheroids formed in a random well was divided by the total number of seeded cells in the well, represented as the percentage. (D) The microscopic images of the spheroids during formation, demonstrating the proliferation of the spheroid from a single cell from day 1 to day

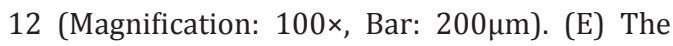
percentage of $\mathrm{CD} 44+\mathrm{CD} 24+\mathrm{ESA}+$ population in Panc-1 parental, spheroid cells cultured by 3D semi-solid system and 3D liquid suspension system respectively. All the results above were represented as mean $\pm \mathrm{SD} \quad(\mathrm{n}=3) . \quad{ }^{*} \mathrm{P}<0.05$; ** $\mathrm{P}<0.01$ compared with parental cells. 


\section{Cellular Physiology Cell Physiol Biochem 2018;47:2109-2125 \begin{tabular}{l|l} 
DOI: 10.1159/000491479 & O 2018 The Author(s). Published by S. Karger AG, Basel \\
www.karger.com/cpb
\end{tabular}

Enrichment of CD44+CD24+ESA+ and CD133+ cells in Panc-1 spheroids

Previous studies have demonstrated that both the CD44+CD24+ESA+ and the CD133+ pancreatic cancer cells showed properties of the PCSCs. Therefore, we examined the expression of these surface markers in cultured Panc-1 spheroids. We found the percentage of CD44+CD24+ESA+ cells in spheroids was $54.63 \%$, which was significantly higher than in their parental counterparts which were $0.46 \%$ (Fig. 1E). Similarly, the percentage of CD133+ cells in spheroids was much higher than its parental counterparts (see online suppl. material, Fig. S1). Beyond that, we found the percentage of cells with PCSC phenotype in Panc-1 spheroids cultured by 3D semi-solid system was much higher than in Panc-1 spheroids cultured by traditional 3D liquid suspension system (Fig. 1E and see online suppl. material, S1). We also examined CD44, CD24, ESA and CD133 mRNA level by qRT-PCR. The expression of these surface markers in Panc-1 spheroids were significantly upregulated compared with the parental counterparts (Fig. 2A), coincides with the flow cytometric results.

Panc-1 spheroid cells express markers for maintaining the CSCs pluripotency

Besides CD24, CD44, CD133, and ESA, there are several other common stem cell markers have been identified as CSCs-specific markers in a variety of CSCs subpopulations, such as aldehyde dehydrogenase 1 (ALDH1), another cell surface marker, and myc-related translation/localization regulatory factor (c-Myc), homeobox protein (Nanog), sex determining region Y-box 2 (Sox-2) and octamer-binding transcription factor 4 (Oct-4), which are typical transcription factors regulating the self-renewal capacity of CSCs [14]. To determine whether the spheroids have acquired stem cell-like features, the spheroids were characterized of their expression levels of the above CSCs markers by qRT-PCR, western blotting and immunofluorescence staining. The mRNA levels of ALDH1, c-Myc, Nanog, Sox-2 and Oct-4 in Panc-1 spheroid cells are higher than in parental counterparts (Fig. 2A). The protein levels of c-Myc, Nanog, Sox-2 and Oct-4 are also increased in Panc-1 spheroid cells (Fig. 2B). By immunofluorescence staining, we found that

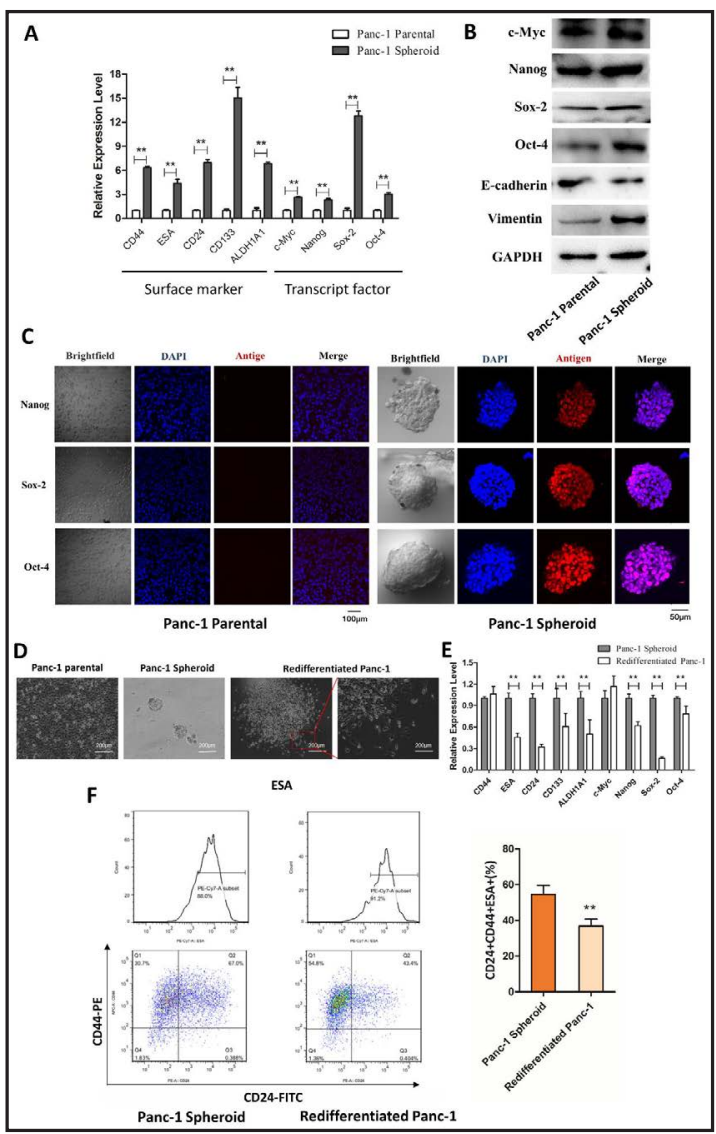

Fig. 2. Characterization of CSC-specific markers in Panc-1 spheroid cells.(A) qRT-PCR analysis of the expression levels of CSC surface markers and pluripotency maintaining markers in Panc-1 parental and spheroid cells. (B) Western blot analysis of the protein levels of c-Myc, Nanog, Sox-2, Oct-4, E-cadherin and Vimentin in Panc-1 parental and spheroid cells. (C) Immunofluorescent staining of Nanog, Sox-2 and Oct-4 in Panc-1 parental and spheroid cells (Magnification: 100×, scale bar: $100 \mu \mathrm{m}$ and Magnification: 400x, scale bar: $50 \mu \mathrm{m}$ ). (D) The morphological changes of Panc-1 spheroid cells after culturing in redifferentiated medium for

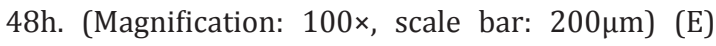
qRT-PCR analysis of the expression levels of CSCs surface markers and pluripotency maintaining markers in Panc-1 spheroid cells and redifferentiated Panc-1 spheroid cells. (F) The percentage of CD44+ CD24+ESA+ population in Panc-1 spheroid cells and redifferentiated Panc-1 spheroid cells respectively. All the results above were represented as mean \pm SD. ${ }^{*} \mathrm{P}<0.05 ;{ }^{* *} \mathrm{P}<0.01$ compared with parental cells. 
Yang et al.: Transcriptome Profiling of Pancreatic Cancer Stem Cells

in the parental cells, the vast majority showed negative staining for Nanog, Sox- 2 and Oct-4 proteins, while they were positively stained within the perinuclear of the Panc- 1 spheroid cells (Fig. 2C).

In addition, the progression of EMT (epithelial mesenchymal transition) was reported more active in PCSCs [15], so we detected the expression of E-cadherin and Vimentin which play important roles during EMT by western blotting, and the results showed that the E-cadherin was down-regulated and Vimentin was up-regulated in Panc-1 spheroid cells (Fig. 2B).

\section{Panc-1 spheroid cells have the potential of differentiation}

CSCs have multilineage differentiation capacity like normal stem cells. So we measured the differentiation capacity of Panc-1 spheroid cells cultured by 3D semi-solid system. Panc1 spheroids were picked at day 11 and dissociated to single cell, then were cultured in the medium supplemented 10\% FBS like the parental cells. After returning to adherent culture for three generations, we observed that Panc- 1 spheroid cells began to adhere to each other and acquired the epithelium-like morphology (Fig. 2D). By qRT-PCR, we detected that most CSCs-related markers had increased in Panc-1 spheroid cells were down-regulated upon redifferentiation (Fig. 2E). In addition, the percentage of CD44+CD24+ESA+ population and $\mathrm{CD} 133+$ population in Panc-1 spheroids were declined after redifferntiation (Fig. 2F and see online suppl. material, S1). These results suggest that Panc-1 spheroid cells have differentiation potential.

Panc-1 spheroid cells obtain the potential of higher proliferation, migration and invasion

PCSCs have been reported to play pivotal roles in proliferation, metastasis and recurrence of pancreatic tumor. We first compared the proliferation capacity between dissociated cells from Panc-1 spheroids and their parental cells through MTT assay and plate colony assay. The growth curve indicated that the Panc-1 spheroid cells exhibited significantly higher proliferation rate (Fig. 3A) and the colony assay showed remarkably larger number of colonies formed by Panc-1 spheroid cells than parental cells (Fig. 3B).

Cell motility can be used to measure the metastasis potential of tumor cells. Compared with Panc-1 parental cells, by wound healing assay and transwell assay, we found spheroid cells migrated faster to close the gap of the scratch (Fig. 3C), and more passed through the transwell membrane (Fig. 3D) than parental cells, suggesting a higher migratory ability of the Panc-1 spheroid cells. In addition, invasion assay was performed, compared to the parental cells, the invasiveness of spheroid cells was higher since there were more cells invaded the matrigel (Fig. 3E). Overall, these data demonstrated that Panc-1 spheroid cells cultured by 3D semi-solid system obtained higher proliferation, migration and invasion ability than parental cells.

Panc-1 spheroid cells develop higher drug resistance to conventional chemotherapies

CSCs play a crucial role in drug resistance which leads to cancer relapse [16]. To verify whether the spheroid cells possess higher chemo-resistance ability, the sensitivity of the parental versus the spheroids to different anti-tumor drugs, gemcitabine, doxorubicin and oxaliplatin was measured. The drug treatment was carried out as described above. The results showed that the survival rates (IC50) under serially diluted drugs for Panc-1 spheroids cells were 1.9-fold, 1.5-fold, 2.8-fold for doxorubicin, gemcitabine and oxaliplatin respectively, compared to the Panc- 1 parental cells (Fig. 3F). Furthermore, we determined the expression levels of two common drug resistance genes, MDR1 and ABCG2, both of them were significantly up-regulated in Panc- 1 spheroid cells (Fig. 3F). Taken together, these results suggested the higher drug resistance of Panc-1 spheroid cells.

Panc-1 spheroid cells have higher tumorigenic potential in vivo

PCSCs with CD44/CD24/ESA or CD133 expression were both reported to exhibit increased tumorigenicity in orthotopic mouse model [2]. Because we have enriched both 
Fig. 3. Comparison of cell proliferation, migration, invasion and drug resistance ability between Panc-1 spheroid cells and Panc-1 parental cells.(A, B) Panc-1 spheroid cells showed higher cell proliferation rate compared to Panc-1 parental cells detected by MTT assay (A) and plate colony assay (B). (C, D) Panc-1 spheroid cells showed higher migration ability compared to Panc-1 parental cells detected by wound healing assay (C) and transwell migration assay (D). (E) Panc-1 spheroid cells showed higher invasion ability compared to Panc-1 parental cells detected by transwell invasion assay. (F) Panc-1 spheroid cells showed higher cell drug resistance ability compared to Panc-1 parental cells. Left panel: the IC50 values $(\mu \mathrm{M})$ of chemotherapy drugs doxorubicin, gemcitabine and oxaliplatin in Panc-1 parental and spheroid cells. Right panel: qRT-PCR analysis of drug resistance genes expressed in Panc-1 parental and spheroid cells. All the results above were represented as mean $\pm \mathrm{SD}$. ${ }^{*} \mathrm{P}<0.05$; ${ }^{* *} \mathrm{P}<0.01$ compared with parental cells.

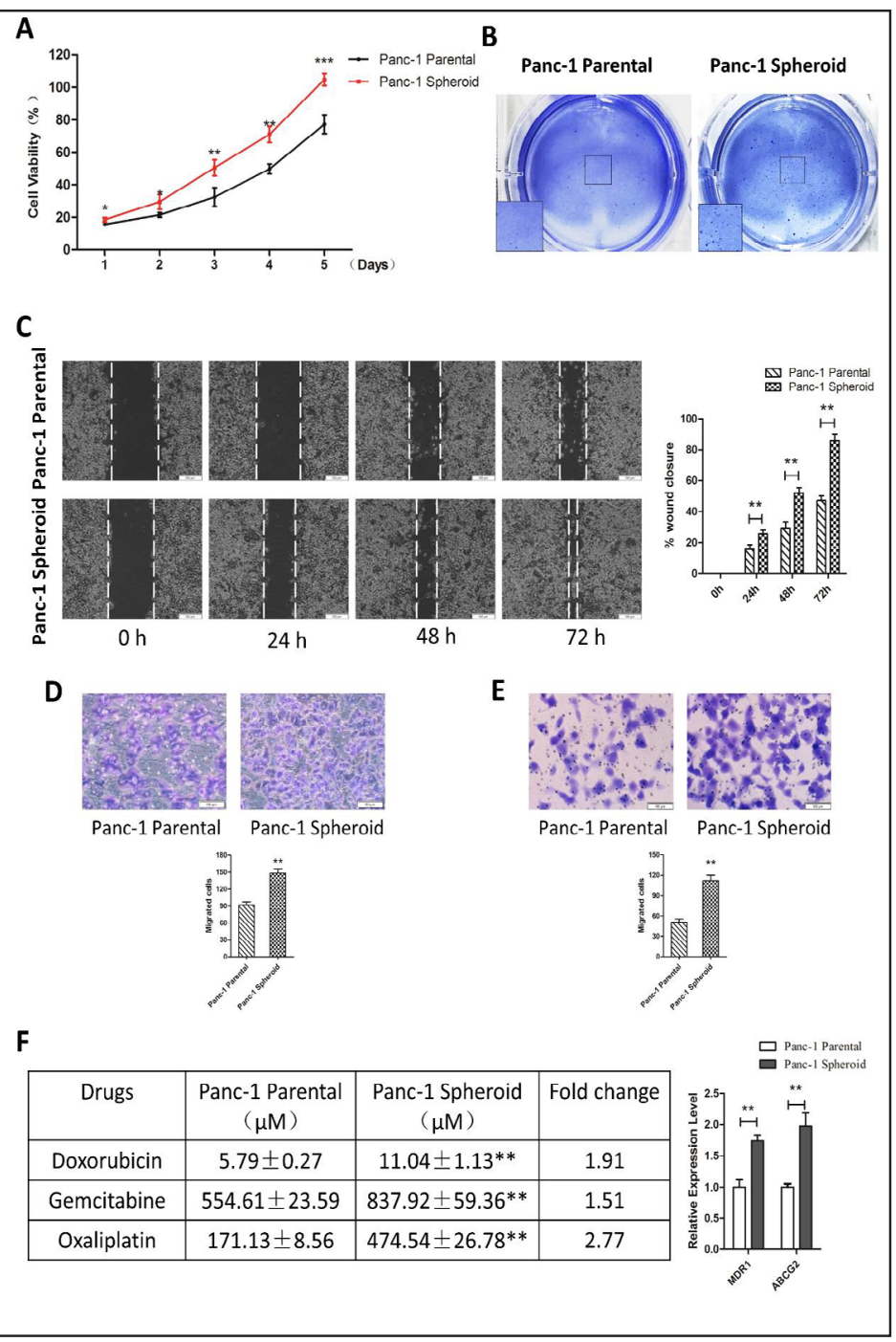

CD44+CD24+ESA+ and CD133+ cells in Panc-1 spheroid cells, we speculated that Panc-1 spheroid cells should also have higher tumorigenic potential than parental cells in mice. Xenograft experiments in immunocompromised mice were performed as described above (Fig. 4A). We observed a significant increase in the size and weight of the tumors in the Panc1 spheroid group compared to Panc-1 parental group (Fig. 4B-E). Besides, in mice injected with Panc-1 spheroid cells, macroscopic tumors were detected in all of the six mice, whereas tumors of much smaller size was observed in four of all the six mice injected with Panc1 parental cells (Fig. 4F). The results indicated that Panc- 1 spheroid cells have enhanced tumorigenic potential.

Furthermore, the tumor formation was confirmed with histologic analysis (Fig. 4G). H\&E staining of xenograft tissues showed a significant difference of histopathologic morphology between two groups. The pathological results of tumors formed from Panc- 1 parental cells closely resembled normal pancreatic ductal epithelial tissue and have low malignancy, while the tumors formed from Panc-1 spheroid showed morphological characteristics of poorly differentiated carcinoma with high malignancy. Vacuoles were also observed because of stromal fibrosis, and more cell mitosis could be seen. We then performed immunehistochemical staining for Ki-67 as a marker to indicate the proliferative activity of tumor cells. The cell proliferation rate was increased in tumors from the group implanted with Panc-1 spheroid cells. These results clearly demonstrated that the Panc-1 spheroids cultured 
by the 3D semi-solid system had enriched PCSCs-like Panc-1 cells with high tumorigenicity, which contributes to the tumor formation in vivo.

\section{High-throughput Sequencing and Transcriptome Profiling of PCSCs-enriched Panc-1 spheroid cells \\ To delve into the crucial} genes which gave Panc1 spheroid cells the PCSCs properties, HTS was performed. Total RNAs including mRNAs, miRNAs and LncRNAs are sequenced and annotated. The significantly changed RNAs in spheroids cells sample were detected using 2-fold expression difference as a cutoff level. According to the data analysis, 479 mRNAs, 283 miRNAs and 34 LncRNAs were identified (Table 1, Fig. 5A and B, Fig. 7A), indicating their potential roles in regulating PCSCs. Original datasets of HTS were provided see online suppl. material, in Table S1 (miRNAs) and see online suppl. material, Table S2 (mRNAs and LncRNAs).

miRNAs function by targeting mRNAs and can serve as early diagnostic biomarker and act as tumor suppressor genes or oncogenes [10]. First, we verified top 20 upregulated and down-regulated miRNAs (see online suppl. material, Table S3), 19 genes showed consistent trend in the data compared to the sequencing result. Among the top 10 miRNAs that we found to be up-regulated, three miRNAs have been reported previously to be associated with pancreatic cancer such as regulating cell survival(miR148a-3p) [17] and cell migration(miR-1-3p) [18],

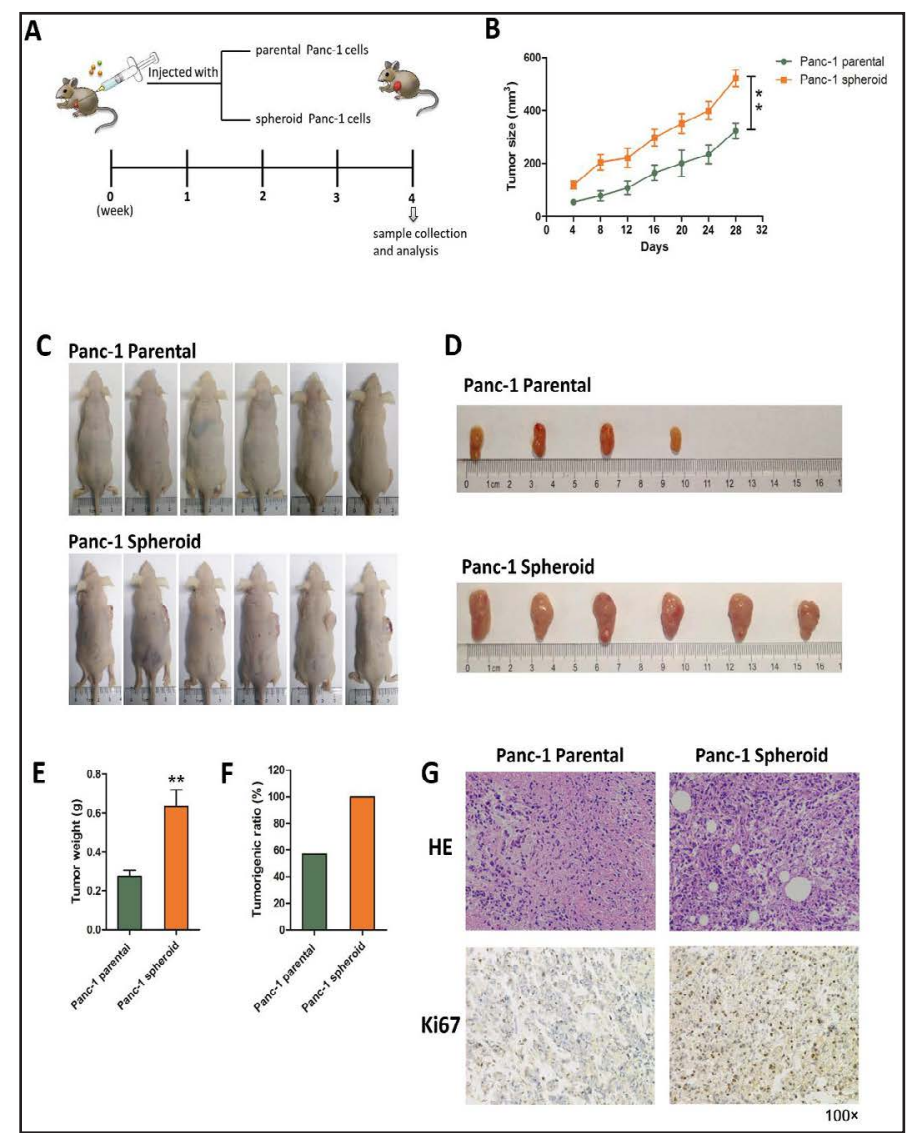

Fig. 4. Tumorigenic potential of Panc-1 spheroid cells in nude mice. (A) Nude mice were divided into 2 groups and subcutaneously injected with Panc-1 parental and spheroid cells in the right axilla of each group, respectively. Four weeks after injection, all the mice were sacrificed and the tumors were stripped and assessed. (B) Growth curve of tumor sizes in Panc-1 parental and spheroid groups. (C) Varying sizes of tumors appeared on the right flank of mice between Panc-1 parental and spheroid groups. (D) Image of the tumors from mice of Panc-1 parental and spheroid groups. (E) Quantitative analysis of the tumors weight in Panc-1 parental and spheroid groups. (F) Tumorigenic rate of Panc-1 parental and spheroid cells. (G) Representative H\&E-stained sections and immunohistochemical staining for Ki-67 of the tumors from mice of Panc- 1 parental and spheroid groups. All the results above were represented as mean $\pm \mathrm{SD}$. ${ }^{*} \mathrm{P}<0.05$; ${ }^{* *} \mathrm{P}<0.01$ compared with parental cells.

Table 1. The number of significantly changed RNAs between the Panc-1 parental and Panc-1 spheroid

\begin{tabular}{lccc}
\hline \multicolumn{4}{c}{ Significant RNA change in the Panc-1 spheroid } \\
\hline URNA & 219 & Down-regulated & Total \\
miRNA & 128 & 260 & 479 \\
IncRNA & 6 & 155 & 283 \\
& & 28 & 34 \\
\hline
\end{tabular}


and as diagnostic biomarkers (miR-20a-5p) [19]. Two miRNAs (miR-374a-3p, miR-340-5p) have yet to be associated with pancreatic cancer but involved in other types of cancer [20, 21]. Furthermore, of the top 10 miRNAs down-regulated in spheroids, five miRNAs (miR486-3p, miR-134-5p, miR-320a, miR-127-3p, and miR-377-3p) have been reported previously to be related to pancreatic cancer, and three of them were found playing an important role in drug resistance (miR320a) [22], cell proliferation (miR-377-3p) [23], or as a tumor suppressor (miR-127-3p) [24], while the other two miRNAs had no further study yet. Four miRNAs, miR-370-3p, miR-1855p, miR-193a-5p and miR-378a$3 p$ were all associated with chemoresistance and involved in other types of cancer [2528]. While the rest haven't been researched in cancers. We also validated 8 other miRNAs in our dataset that have been reported to be regulated in pancreatic cancer $[29,30]$, coincidentally, they were also regulated in Panc1 spheroid cells (Fig. 5C). Among them, miR-21, miR-31-3p, miR203, miR-16 were up-regulated which were found to be engaged in regulating apoptosis (miR21) [31], migration and invasion

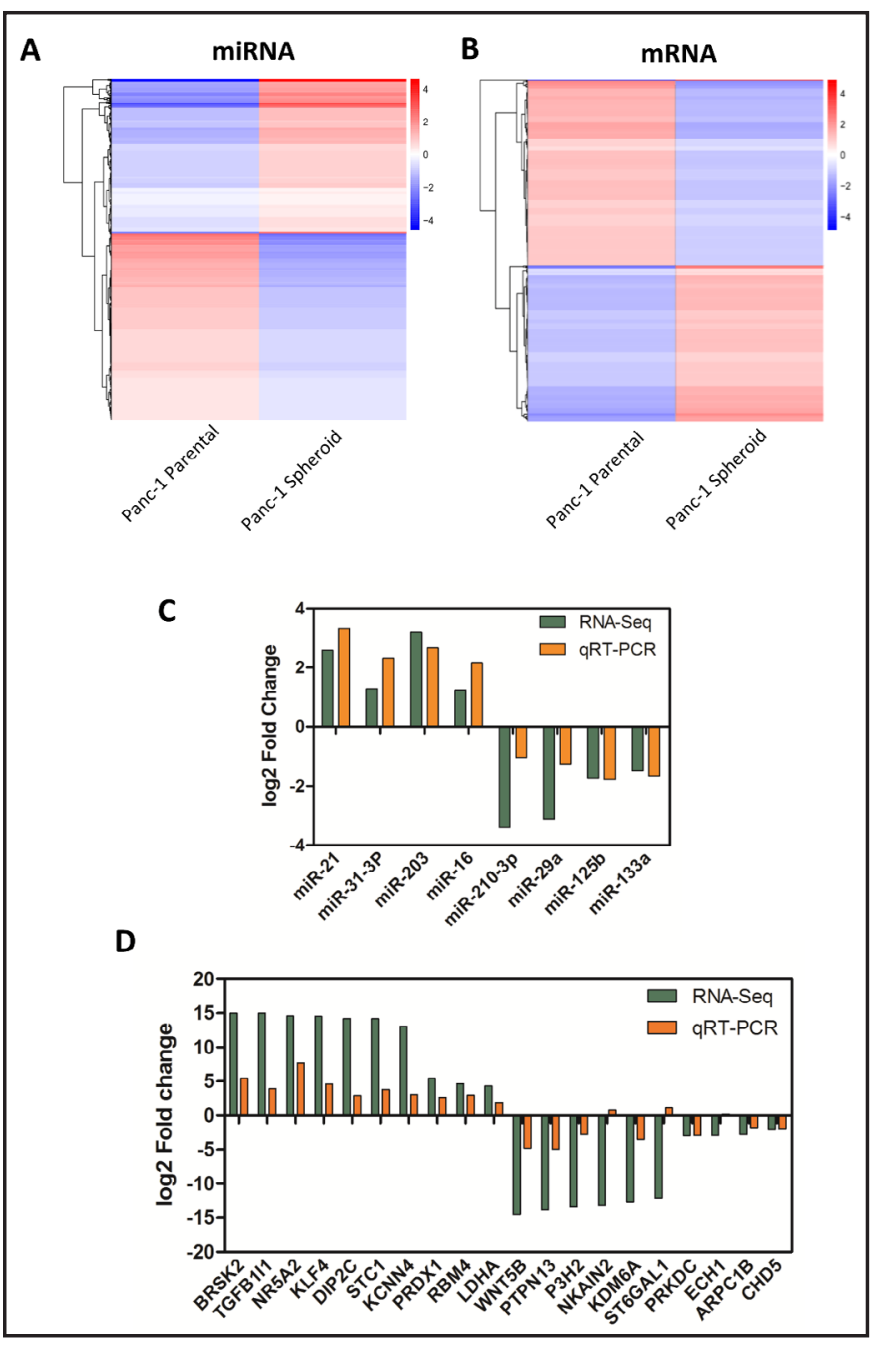

Fig. 5. Differentially expressed miRNAs and mRNAs detected by HTS and verified by qRT-PCR.(A, B). The heat maps of all miRNAs (A) and mRNAs (B) showed the differences of the transcriptome between Panc-1 spheroid cells and parental cells. Each group contains three batches of individual samples, which were pooled and mixed. (C, D) Verification of the differentially expressed miRNAs (C) and mRNAs (D) by qRT-PCR. (miR-31 and miR-203) [32, 33], and diagnosis(miR-16) [34] of pancreatic cancer. On the other hand, miR-210-3p, miR-29a, miR-125b, miR-133a were down-regulated, they have been reported to be associated with pancreatic cancer such as regulating cells interaction (miR-210) [35], as an autophagy inhibitor (miR-29a) [36], as a tumor suppressor(miR-125b and miR-133a) [36]. However, none of the miRNAs above is well characterized in PCSCs.

Next, we validated 20 up- and down- regulated mRNAs which have been previously reported in pancreatic cancer or other types of cancer by qRT-PCR, and we found 17 of them showed consistent trend with the sequencing data (see online suppl. material, Tab. S5 and Fig. 5D), which suggests that many genes that participate in the progression of pancreatic cancer or other cancers may also play roles in PCSCs regulation. Among up-regulated mRNA, BRSK2 (brain-selective kinase 2) was the most significantly changed. High expression of BRSK2 in pancreatic ductal adenocarcinoma (PDAC) is usually accompanied by lymphatic metastasisdistant metastasis, TNM (tumor lymph nodes metastasis) late stage as well as 


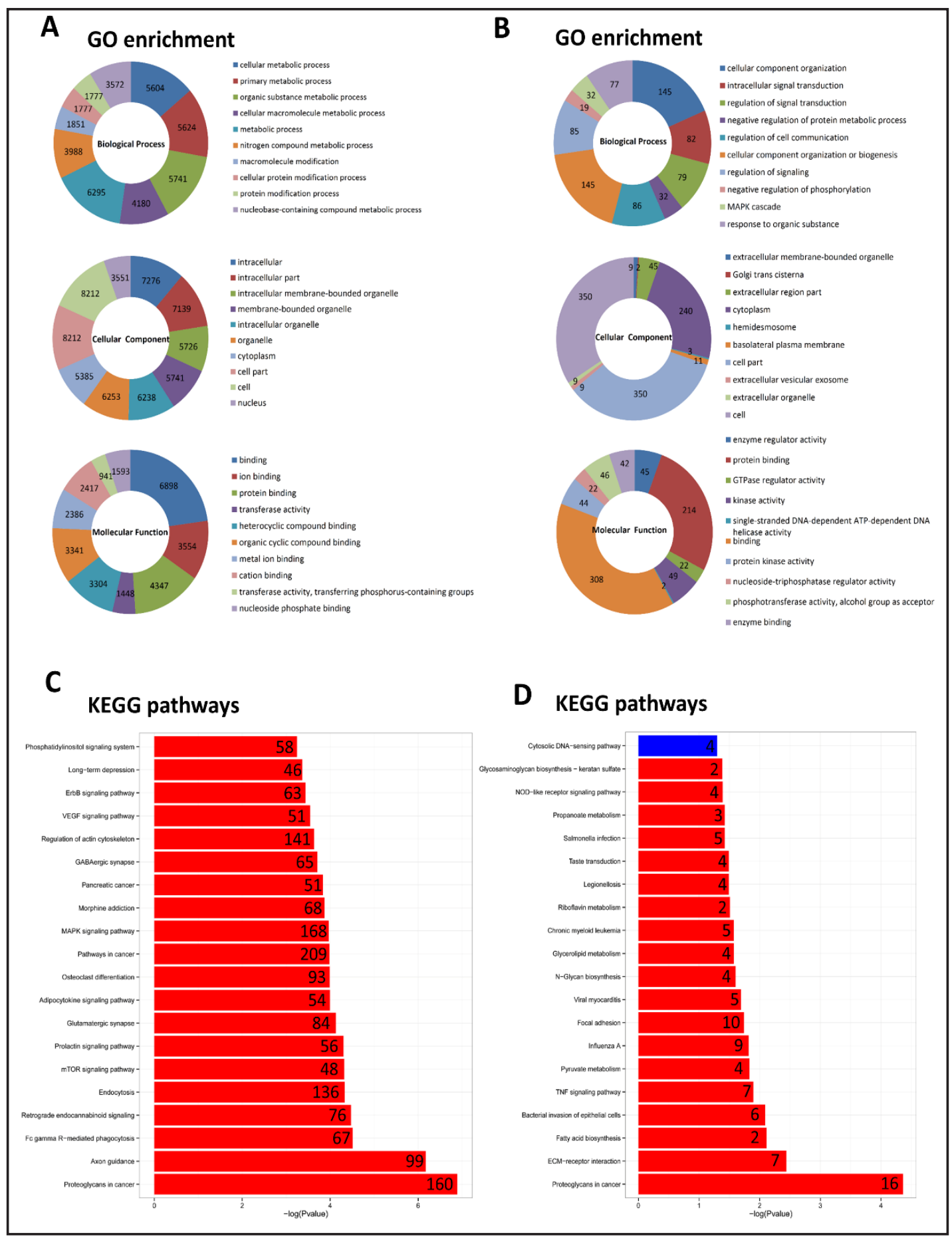

Fig. 6. GO and KEGG enrichment analysis of miRNAs and mRNAs.(A, B) GO enrichment of significantly changed miRNAs (A) and mRNAs (B). Top 10 categories (by p-value) of each GO dataset were shown. Numbers in each part of the graph stand for the gene counts in each GO dataset. (C, D) Top 20 (by p-value) of enriched KEGG pathways of miRNAs (C) and miRNAs (D) were listed. Numbers on each top of the columns stand for the gene counts in each KEGG pathways.

peri-pancreatic neural invasion [37]. TGFB1I1 (TGF- $\beta 1$ induced transcript 1 ) is reported to contribute to malignant progression of astrocytomas by inducing EMT [38]. Interestingly, recent study demonstrated that NR5A2 (nuclear receptor 5A2) was highly expressed in 
pancreatic cancer sphere cells, which is consistent with our sequencing results. NR5A2 inhibition could reduce sphere formation, decrease levels of CSCs markers, and inhibit EMT [39]. KLF4 (Krüppel-like factors 4) is found highly expressed in stem cells, pancreatic cancer cells and some other CSCs. It participates in stemness maintenance and facilitates the self-renewal and proliferation potential of CSCs [40]. Among the downregulated mRNAs, WNT5B (Wnt family member 5B) was prominently decreased, which was known to play a critical role in embryonic development by regulating cell growth and differentiation. It was also found negatively related with the malignancy of liver CSCs [41]. PTPN13 (protein tyrosine phosphatase non-receptor type 13) was found down-regulated in various cancers as tumor suppressor gene and could affect the aggressiveness and susceptibility of cancer cells [42]. Our finding suggests that the significant differentially expressed genes may be involved in stemness maintenance and malignancy of PCSCs.

LncRNAs are believed to regulate gene expression through many mechanisms which have already been reported to be involved in pancreatic cancer [43]. In our study, we predicted the targets of all the LncRNAs in our high throughput sequencing according to the starBase v2.0, AnnoLnc and NONCODE. And we verified all the LncRNAs with clear potential targets by qRT-PCR (Fig. 7B and see online suppl. material, Table S6). The result showed that the trend of these LncRNAs about $90 \%$ consistent with the sequencing results. Among them, IncRNA MEG3 has been shown to be able to regulate cell proliferation via activation of p53 in pancreatic cancer while others haven't been studied. So far, little is known about these LncRNAs in PCSCs regulation.

\section{GO and KEGG enrichment of target genes}

Gene Ontology (GO) is a dataset to annotate the molecular function, biological processes and cellular components of the target genes that are differentially expressed. Each GO category contains many terms which represent the significantly enriched sub-categories which those differentially expressed genes distribute into. The top 10 GO terms of each category of the differentially expressed genes in Panc-1 spheroids (listed by $p$-value) were shown (Fig. 6A and B, see online suppl. material, Fig. S2A). For predicted miRNAs targets 
(Fig. 6A), differentially expressed genes enriched in the molecular functions of "binding", "ion binding" and "protein binding"; the cellular components of "cell", "cell part" and "intracellular"; the biological processes of "metabolic process", "organic substance metabolic process" and "primary metabolic process". In mRNA (Fig. 6B), differentially expressed genes were enriched in the molecular functions of "binding", "protein binding" and "protein kinase activity"; the cellular components of "cell", "cell part" and "cytoplasm" and the biological processes of cellular component organization or biogenesis", "cellular component organization" and "regulation of cell communication". For LncRNA targets, top GO terms were shown see online suppl. material, in Fig. S1A.

To improve our understanding of the pathways involving the differentially expressed genes, the KEGG analysis was performed. The KEGG analysis of miRNA target genes showed that "Proteoglycans in cancer" was the most enriched pathways (Fig. 6C). Pathways enriched the most in mRNA transcriptome were "Proteoglycans in cancer" and "ECM-receptor interaction" (Fig. 6D). Pathways enriched in LncRNA target genes were shown see online suppl. material, in Fig. S2B.

To find the key mRNAs regulated by non-coding RNA network, we performed coexpression analysis of differentially expressed RNAs between the Panc- 1 spheroid and parental cells. The intersection of significantly changed mRNAs and the potential targets of significantly changed non-coding RNAs were obtained (Fig. 7C). Overlapped genes and the counts were listed (see online suppl. material, Table S7) and GO and KEGG pathways were analyzed (see online suppl. material, Fig. S2C and D).

\section{Discussion}

Pancreatic cancer is a highly complex and aggressive malignancy with early local invasion and metastasis, and is resistant to most therapies, all of which are believed to contribute to its extremely poor prognosis. Given that PCSCs have a crucial role not only in tumor initiation and progression, but also in drug resistance and relapse or recurrence of pancreatic cancer, they emerge as an excellent target for developing effective novel therapeutic approaches.

In the present study, we aimed at identifying the crucial genes involved in the regulation of PCSCs. We first established a novel 3D semi-solid spheroids culture model of pancreatic cancer cell line, Panc- 1 . And we also confirmed that the Panc- 1 spheroid cells possess PCSCs properties and high malignancy in vitro and in vivo. We then performed comprehensive analysis of the different RNAs transcriptomic profiles between Panc- 1 parental cells by monolayer culture model and Panc- 1 spheroid cells by 3D semi-solid culture model and found several mRNAs, miRNAs and LncRNAs that were differentially expressed in the Panc1 spheroid cells. Therefore, our study could provide a ground work for the future cancer researchers to improve the diagnosis or therapy of pancreatic cancer especially in PCSCs studies.

Due to the limitation of acquisition, identification and culture of tumor-derived PCSCs, previous researches encriched PCSCs in vitro by culturing pancreatic cancer cells in liquid suspension culture system as spheroid cells [15]. However, this kind of spheroid might form cells aggregation. In our study, the application of methylcellulose allowed the single cell to form spheroids that were homogenous in origin as reported [44]. We confirmed the ultrastructure of the Panc-1 spheroids and detected strong cell-cell junction within the Panc1 spheroids that supported its shape by SEM analysis (Fig. 1B). We evaluated the PCSCs properties in Panc-1 spheroids cells based on their self-renewal capacity, expression of PCSCs-related markers, differentiation potential, proliferation capacity, metastasis ability and chemoresistance [45]. In our results, Panc-1 spheroid cells could form secondary spheroids and were able to be serially cultured, demonstrating that these cells preserved the ability of self-renewal and extended proliferation properties which are consistent with the previous studies [46]. Cultured PCSCs from pancreatic cancer are known to exhibit distinct cell surface antigens such as CD44, CD24, ESA and CD133 [15]. We found both CD44+CD24+ESA+ cell population and CD133+ cell population were enriched in Panc-1 spheroid cells compared 
with their parental. In addition, several transcription factors like Nanog, Sox-2, Oct-4 and c-Myc, which are commonly used as pluripotency-like markers of CSCs [47, 48], were also expressed in Panc-1 spheroids. Furthermore, after culturing the cells from the spheroids back to common medium supplemented with $10 \%$ FBS, the CD44+CD24+ESA+ cell population and CD133+ cell population proportion were decreased, the cell morphology was changed, and the stemness markers were down-regulated, all of which indicated that the cells have differentiated. The proliferative ability of Panc- 1 spheroid cells was detected by MTT assay and plate colony assay, and Panc- 1 spheroid cells showed higher proliferation potential than their parental cells. Inappropriate activation of the EMT processes, is reported to contribute in part to the increased invasive and metastatic potential of various CSCs . Our data proved that E-cadherin was down-regulated and Vimentin was up-regulated in Panc- 1 spheroid cells which indicated the activation of EMT. The wound healing and transwell assays also demonstrated Panc-1 spheroid cells had higher metastasis ability. Chemosensitivity assays showed that the cells from Panc-1 spheroids had higher drug resistance to the common chemotherapeutic drugs than that of the parental cells. In addition, the data also suggested that the Panc-1 spheroids cells displayed higher tumorigenic ability in vivo. All the results above indicated the enrichment of PCSCs-like cells in Panc-1 spheroids cultured by our novel 3D semi-solid system.

To identify the crucial genes and signaling pathways that lead to different characteristics between Panc-1 spheroid and parental cells, which may help provide new therapeutic targets for pancreatic cancer, we employed HTS technique to explore the transcriptome of Panc-1 spheroid cells. We obtained 479 significantly changed mRNAs along with 283 miRNAs, 34 LncRNAs. miRNA has been shown to be closely related to pancreatic cancer $[49,50]$. The important roles of most of the miRNAs in our list is still unclear in PCSCs, while only miR-125b and miR-34a has been reported in CSCs. These remarkable changed miRNAs in our results are strong candidates to be further explored in discovering the novel regulatory mechanisms in PCSCs regulation. We also noted that among the differently expressed mRNAs, BRSK2 was up-regulated the most, which has been reported to promote cancer cells metastasis and decrease the metabolism of cancer cells to help them resist harsh environments [37]. NR5A2 and KLF4 both have been found associated with other CSCs function such as stemness maintenance, self-renewal and EMT. WNT5B was down-regulated a lot, which was involved the malignancy of liver CSCs [41]. These genes may be related to stemness maintenance and malignancy of PCSCs. It is worth noting that the surface markers of PCSCs such as CD24, CD44 and CD133 are highly expressed in Panc-1 spheroid cells, which indicates that Panc1 spheroids are enriched of PCSCs. LncRNA is another group of non-coding RNA involved in pancreatic cancer by regulating cell metastasis, proliferation and apoptosis by different mechanisms [50-52], which also plays an important role in CSCs [52-54]. And our profiling of PCSCs showed 34 differently expressed LncRNAs, among which, MEG3 has been shown to be able to regulate cell proliferation via activation of p53 in pancreatic cancer $[53,55]$, while others have not been reported yet on cancers, but have numerous potential targets predicted by several LncRNA target-predicting programs. For the RNAs we are interested in, we may study them with further verification of their expression in tumor-derived PCSCs and spheroid cells from other pancreatic cancer cell line.

The GO terms and KEGG pathways enrichment analysis of the miRNAs and LncRNAs found in the Panc-1 spheroids revealed the functions of those RNAs in PCSCs. We note that the term "protein binding" was enriched in the molecular functions of both mRNA and miRNA. Many protein-binding molecules have been reported to be involved in different biological processes [54, 56]. In KEGG analysis of mRNA and miRNA, the "proteoglycans in cancer" pathway is the most significant. Proteoglycans have been shown to play an important role in regulating cancer progression [55, 57]. Furthermore, stemness can also be regulated by some proteoglycans $[56,58]$. It is likely that PCSCs may share some common regulated pathways with other kinds of CSCs.

With limited treatment options, poor prognosis and frequent relapse of pancreatic cancer, discovery and better understanding the roles of key genes leading to PCSCs 
Yang et al.: Transcriptome Profiling of Pancreatic Cancer Stem Cells

maintenance and malignancy are in great need in the treatment of pancreatic cancer. In our study, we provide a novel 3D semi-solid system for culturing PCSCs-like Panc-1 which makes it possible for the study of PCSCs. Furthermore, our study is the first investigation performing comprehensive comparisons in terms of the RNAs expression in the PCSCs, which provides valuable information to improve the current understanding of the pancreatic cancer carcinogenesis mechanisms. It also provides a foundation for the development and novel discovery of molecular therapies targeting PCSCs.

\section{Acknowledgements}

We are grateful to Huiqian Huang (California Institute of Technology) for critical reviewing and editing the paper as well as providing some scientific advice. This project is funded by National Natural Science Foundation of China (Grant No. 81570696 and No. 81702941); Supported by Qing Lan Project; Supported by Program for Jiangsu Province Innovative Research Team; Supported by Priority Academic Program Development of Jiangsu Higher Education Institutions, Top-notch Academic Programs Project of Jiangsu Higher Education Institutions (PPZY2015A057); and the Fundamental Research Funds for the Central Universities (2016ZPY010, 2632017PY06). YP and LJ designed and supervised the study and experiments, analyzed the data, and co-wrote the manuscript. ZCY, YFZ, TTT, QHZ, WYS, XY, YX and YMS performed the experiments, analyzed the data. All authors read and approved the final manuscript.

\section{Disclosure Statement}

The authors declare that they have no competing interests.

\section{References}

$\checkmark 1$ Iovanna J, Neira JL: Pancreatic cancer: molecular, biochemical, chemopreventive, and therapeutic aspects. ScientificWorldJournal 2010;10:1967-1970.

2 Li C, Heidt DG, Dalerba P, Burant CF, Zhang L, Adsay V, Wicha M, Clarke MF, Simeone DM: Identification of pancreatic cancer stem cells. Cancer Res 2007;67:1030-1037.

-3 Hermann PC, Huber SL, Herrler T, Aicher A, Ellwart JW, Guba M, Bruns CJ, Heeschen C: Distinct populations of cancer stem cells determine tumor growth and metastatic activity in human pancreatic cancer. Cell Stem Cell 2007;1:313-323.

4 Reya T, Morrison SJ, Clarke MF, Weissman IL: Stem cells, cancer, and cancer stem cells. Nature 2001;414:105-111.

5 Imamura Y, Mukohara T, Shimono Y, Funakoshi Y, Chayahara N, Toyoda M, Kiyota N, Takao S, Kono S, Nakatsura T, Minami H: Comparison of 2D- and 3D-culture models as drug-testing platforms in breast cancer. Oncol Rep 2015;33:1837-1843.

-6 Singec I, Knoth R, Meyer RP, Maciaczyk J, Volk B, Nikkhah G, Frotscher M, Snyder EY: Defining the actual sensitivity and specificity of the neurosphere assay in stem cell biology. Nat Methods 2006;3:801-806.

$\checkmark 7$ Lawson DA, Xin L, Lukacs RU, Cheng D, Witte ON: Isolation and functional characterization of murine prostate stem cells. Proc Natl Acad Sci U S A 2007;104:181-186.

$>8$ Boo L, Ho WY, Ali NM, Yeap SK, Ky H, Chan KG, Yin WF, Satharasinghe DA, Liew WC, Tan SW, Ong HK, Cheong SK: MiRNA Transcriptome Profiling of Spheroid-Enriched Cells with Cancer Stem Cell Properties in Human Breast MCF-7 Cell Line. Int J Biol Sci 2016;12:427-445.

9 Jiang J, Li Z, Yu C, Chen M, Tian S, Sun C: MiR-1181 inhibits stem cell-like phenotypes and suppresses SOX2 and STAT3 in human pancreatic cancer. Cancer Lett 2015;356:962-970.

10 Pan Y, Liang H, Chen W, Zhang H, Wang N, Wang F, Zhang S, Liu Y, Zhao C, Yan X, Zhang J, Zhang CY, Gu H, Zen $\mathrm{K}$, Chen X: microRNA-200b and microRNA-200c promote colorectal cancer cell proliferation via targeting the reversion-inducing cysteine-rich protein with Kazal motifs. RNA Biol 2015;12:276-289.

11 Pan Y, Li J, Zhang Y, Wang N, Liang H, Liu Y, Zhang CY, Zen K, Gu H: Slug-upregulated miR-221 promotes 


\section{Cellular Physiology Cell Physiol Biochem 2018;47:2109-2125 \begin{tabular}{l|l} 
and Biochemistry Published onine: July 04, 2018 & $\begin{array}{l}\text { (c) } 2018 \text { The Author(s). Published by S. Karger AG, Basel } \\
\text { www.karger.com/cpb }\end{array}$
\end{tabular}}

Yang et al.: Transcriptome Profiling of Pancreatic Cancer Stem Cells

breast cancer progression through suppressing E-cadherin expression. Sci Rep 2016;6:25798.

12 Mosmann T: Rapid colorimetric assay for cellular growth and survival: application to proliferation and cytotoxicity assays. J Immunol Methods 1983;65:55-63.

13 Jin L, Feng T, Shih HP, Zerda R, Luo A, Hsu J, Mahdavi A, Sander M, Tirrell DA, Riggs AD, Ku HT: Colonyforming cells in the adult mouse pancreas are expandable in Matrigel and form endocrine/acinar colonies in laminin hydrogel. Proc Natl Acad Sci U S A 2013;110:3907-3912.

-14 Rao CV, Mohammed A: New insights into pancreatic cancer stem cells. World J Stem Cells 2015;7:547-555.

15 Wang F, Ma L, Zhang Z, Liu X, Gao H, Zhuang Y, Yang P, Kornmann M, Tian X, Yang Y: Hedgehog Signaling Regulates Epithelial-Mesenchymal Transition in Pancreatic Cancer Stem-Like Cells. J Cancer 2016;7:408417.

16 Wang Z, Li Y, Ahmad A, Banerjee S, Azmi AS, Kong D, Sarkar FH: Pancreatic cancer: understanding and overcoming chemoresistance. Nat Rev Gastroenterol Hepatol 2011;8:27-33.

17 Liffers ST, Munding JB, Vogt M, Kuhlmann JD, Verdoodt B, Nambiar S, Maghnouj A, Mirmohammadsadegh A, Hahn SA, Tannapfel A: MicroRNA-148a is down-regulated in human pancreatic ductal adenocarcinomas and regulates cell survival by targeting CDC25B. Lab Invest 2011;91:1472-1479.

18 Li L, Li B, Chen D, Liu L, Huang C, Lu Z, Lun L, Wan X: miR-139 and miR-200c regulate pancreatic cancer endothelial cell migration and angiogenesis. Oncol Rep 2015;34:51-58.

19 Yuan W, Tang W, Xie Y, Wang S, Chen Y, Qi J, Qiao Y, Ma J: New combined microRNA and protein plasmatic biomarker panel for pancreatic cancer. Oncotarget 2016;7:80033-80045.

20 Wu H, Liu Y, Shu XO, Cai Q: MiR-374a suppresses lung adenocarcinoma cell proliferation and invasion by targeting TGFA gene expression. Carcinogenesis 2016;37:567-575.

21 Wozniak M, Sztiller-Sikorska M, Czyz M: Diminution of miR-340-5p levels is responsible for increased expression of ABCB5 in melanoma cells under oxygen-deprived conditions. Exp Mol Pathol 2015;99:707716.

-22 Wang W, Zhao L, Wei X, Wang L, Liu S, Yang Y, Wang F, Sun G, Zhang J, Ma Y, Zhao Y, Yu J: MicroRNA-320a promotes 5-FU resistance in human pancreatic cancer cells. Sci Rep 2016;6:27641.

23 Chang W, Liu M, Xu J, Fu H, Zhou B, Yuan T, Chen P: MiR-377 inhibits the proliferation of pancreatic cancer by targeting Pim-3. Tumour Biol 2016;37:14813-14824.

-24 Yu Y, Liu L, Ma R, Gong H, Xu P, Wang C: MicroRNA-127 is aberrantly downregulated and acted as a functional tumor suppressor in human pancreatic cancer. Tumour Biol 2016;37:14249-14257.

25 Chen XP, Chen YG, Lan JY, Shen ZJ: MicroRNA-370 suppresses proliferation and promotes endometrioid ovarian cancer chemosensitivity to cDDP by negatively regulating ENG. Cancer Lett 2014;353:201-210.

26 Pei K, Zhu JJ, Wang CE, Xie QL, Guo JY: MicroRNA-185-5p modulates chemosensitivity of human non-small cell lung cancer to cisplatin via targeting ABCC1. Eur Rev Med Pharmacol Sci 2016;20:4697-4704.

27 Jacques C, Calleja LR, Baud'huin M, Quillard T, Heymann D, Lamoureux F, Ory B: miRNA-193a-5p repression of p73 controls Cisplatin chemoresistance in primary bone tumors. Oncotarget 2016;7:54503-54514.

28 Ikeda K, Horie-Inoue K, Ueno T, Suzuki T, Sato W, Shigekawa T, Osaki A, Saeki T, Berezikov E, Mano H, Inoue S: miR-378a-3p modulates tamoxifen sensitivity in breast cancer MCF-7 cells through targeting GOLT1A. Sci Rep 2015;5:13170.

-29 Lee EJ, Gusev Y, Jiang J, Nuovo GJ, Lerner MR, Frankel WL, Morgan DL, Postier RG, Brackett DJ, Schmittgen TD: Expression profiling identifies microRNA signature in pancreatic cancer. Int J Cancer 2007;120:10461054.

-30 Rachagani S, Kumar S, Batra SK: MicroRNA in pancreatic cancer: pathological, diagnostic and therapeutic implications. Cancer Lett 2010;292:8-16.

31 Liu Z, Zhang J, Hong G, Quan J, Zhang L, Yu M: Propofol inhibits growth and invasion of pancreatic cancer cells through regulation of the miR-21/Slug signaling pathway. Am J Transl Res 2016;8:4120-4133.

-32 Laurila EM, Sandstrom S, Rantanen LM, Autio R, Kallioniemi A: Both inhibition and enhanced expression of miR-31 lead to reduced migration and invasion of pancreatic cancer cells. Genes Chromosomes Cancer 2012;51:557-568.

-33 Ren ZG, Dong SX, Han P, Qi J: miR-203 promotes proliferation, migration and invasion by degrading SIK1 in pancreatic cancer. Oncol Rep 2016;35:1365-1374.

-34 Gao L, He SB, Li DC: Effects of miR-16 plus CA19-9 detections on pancreatic cancer diagnostic performance. Clin Lab 2014;60:73-77.

35 Takikawa T, Masamune A, Hamada S, Nakano E, Yoshida N, Shimosegawa T: miR-210 regulates 


\section{Cellular Physiology Cell Physiol Biochem 2018;47:2109-2125 \begin{tabular}{ll|l} 
and Biochemistry Published online: July 04, 2018 & $\begin{array}{l}\text { (c) } 2018 \text { The Author(s). Published by S. Karger AG, Basel } \\
\text { www.karger.com/cpb }\end{array}$ \\
\hline
\end{tabular}}

the interaction between pancreatic cancer cells and stellate cells. Biochem Biophys Res Commun 2013;437:433-439.

-36 Kwon JJ, Willy JA, Quirin KA, Wek RC, Korc M, Yin XM, Kota J: Novel role of miR-29a in pancreatic cancer autophagy and its therapeutic potential. Oncotarget 2016;7:71635-71650.

-37 Guo Z, Tang W, Yuan J, Chen X, Wan B, Gu X, Luo K, Wang Y, Yu L: BRSK2 is activated by cyclic AMPdependent protein kinase A through phosphorylation at Thr260. Biochem Biophys Res Commun 2006;347:867-871.

38 Liu Y, Hu H, Wang K, Zhang C, Wang Y, Yao K, Yang P, Han L, Kang C, Zhang W, Jiang T: Multidimensional analysis of gene expression reveals TGFB1I1-induced EMT contributes to malignant progression of astrocytomas. Oncotarget 2014;5:12593-12606.

-39 Luo Z, Li Y, Zuo M, Liu C, Yan D, Wang H, Li D: Effect of NR5A2 inhibition on pancreatic cancer stem cell (CSC) properties and epithelial-mesenchymal transition (EMT) markers. Mol Carcinog 2017;56:1438-1448.

40 Leng Z, Tao K, Xia Q, Tan J, Yue Z, Chen J, Xi H, Li J, Zheng H: Kruppel-like factor 4 acts as an oncogene in colon cancer stem cell-enriched spheroid cells. PLoS One 2013;8:e56082.

41 Sun D, Qin L, Xu Y, Liu JX, Tian LP, Qian HX: Influence of adriamycin on changes in Nanog, Oct-4, Sox2, ARID1 and Wnt5b expression in liver cancer stem cells. World J Gastroenterol 2014;20:6974-6980.

42 Zhan H, Jiang J, Luo C, Sun Q, Ke A, Sun C, Hu J, Hu Z, Hu B, Zhu K, Fan J, Zhou J, Huang X: Tumoursuppressive role of PTPN13 in hepatocellular carcinoma and its clinical significance. Tumour Biol 2016;37:9691-9698.

43 Peng JF, Zhuang YY, Huang FT, Zhang SN: Noncoding RNAs and pancreatic cancer. World J Gastroenterol 2016;22:801-814.

44 Jin L, Feng T, Zerda R, Chen CC, Riggs AD, Ku HT: In vitro multilineage differentiation and self-renewal of single pancreatic colony-forming cells from adult C57BL/6 mice. Stem Cells Dev 2014;23:899-909.

45 Cao L, Zhou Y, Zhai B, Liao J, Xu W, Zhang R, Li J, Zhang Y, Chen L, Qian H, Wu M, Yin Z: Sphere-forming cell subpopulations with cancer stem cell properties in human hepatoma cell lines. BMC Gastroenterol 2011;11:71.

46 Liu J, Ma L, Xu J, Liu C, Zhang J, Liu J, Chen R, Zhou Y: Spheroid body-forming cells in the human gastric cancer cell line MKN-45 possess cancer stem cell properties. Int J Oncol 2013;42:453-459.

47 Wang J, Wang H, Li Z, Wu Q, Lathia JD, McLendon RE, Hjelmeland AB, Rich JN: c-Myc is required for maintenance of glioma cancer stem cells. PLoS One 2008;3:e3769.

48 Yan W, Chen Y, Yao Y, Zhang H, Wang T: Increased invasion and tumorigenicity capacity of CD44+/CD24breast cancer MCF7 cells in vitro and in nude mice. Cancer Cell Int 2013;13:62.

49 Vorvis C, Koutsioumpa M, Iliopoulos D: Developments in miRNA gene signaling pathways in pancreatic cancer. Future Oncol 2016;12:1135-1150.

50 Zhou B, Sun C, Hu X, Zhan H, Zou H, Feng Y, Qiu F, Zhang S, Wu L, Zhang B: MicroRNA-195 Suppresses the Progression of Pancreatic Cancer by Targeting DCLK1. Cell Physiol Biochem 2017;44:1867-1881.

51 Kim K, Jutooru I, Chadalapaka G, Johnson G, Frank J, Burghardt R, Kim S, Safe S: HOTAIR is a negative prognostic factor and exhibits pro-oncogenic activity in pancreatic cancer. Oncogene 2013;32:1616-1625.

52 Jiao F, Hu H, Han T, Yuan C, Wang L, Jin Z, Guo Z, Wang L: Long noncoding RNA MALAT-1 enhances stem celllike phenotypes in pancreatic cancer cells. Int J Mol Sci 2015;16:6677-6693.

53 Li H, An J, Wu M, Zheng Q, Gui X, Li T, Pu H, Lu D: LncRNA HOTAIR promotes human liver cancer stem cell malignant growth through downregulation of SETD2. Oncotarget 2015;6:27847-27864.

54 Pan Y, Li C, Chen J, Zhang K, Chu X, Wang R, Chen L: The Emerging Roles of Long Noncoding RNA ROR (lincRNA-ROR) and its Possible Mechanisms in Human Cancers. Cell Physiol Biochem 2016;40:219-229.

55 Hu D, Su C, Jiang M, Shen Y, Shi A, Zhao F, Chen R, Shen Z, Bao J, Tang W: Fenofibrate inhibited pancreatic cancer cells proliferation via activation of p53 mediated by upregulation of LncRNA MEG3. Biochem Biophys Res Commun 2016;471:290-295.

56 Squillaro T, Alessio N, Cipollaro M, Renieri A, Giordano A, Galderisi U: Partial silencing of methyl cytosine protein binding 2 (MECP2) in mesenchymal stem cells induces senescence with an increase in damaged DNA. FASEB J 2010;24:1593-1603.

-57 Baghy K, Tatrai P, Regos E, Kovalszky I: Proteoglycans in liver cancer. World J Gastroenterol 2016;22:379393.

58 Toh YC, Voldman J: Fluid shear stress primes mouse embryonic stem cells for differentiation in a selfrenewing environment via heparan sulfate proteoglycans transduction. FASEB J 2011;25:1208-1217. 